\title{
Penentuan Bobot Kriteria Pemilihan Alternatif Online-Shop dalam Memasarkan Produk Kosmetik dengan Menggunakan Analytical Hierarchy Process (AHP)
}

\author{
Ruri Artanti Prahastuti ${ }^{1,}{ }^{*}$, Julianus Hutabarat $^{2}$, Dimas Indra Laksmana ${ }^{3}$ \\ 1,2,3 (Teknik dan Manajemen Industri Pascasarjana Institut Teknologi Nasional Malang) \\ *Email: mynameisruri23@gmail.com
}

\begin{abstract}
Abstrak
Kriteria pemilihan suatu alternatif menjadi suatu hal yang penting dalam membuat keputusan, tidak kecuali dalam pemilihan alternatif online-shop, kriteria merupakan alat ukur untuk pemilihan alternatif, yang menjadi persoalan bagaimana untuk membangkitkan kriteria yang baik dalam membuat keputusan. Tujuan dari penelitian ini adalah bagaimana membangkitkan kriteria yang akan dijadikan sebagai alat ukur untuk memutuskan pemilihan alternatif online-shop. Untuk mencapai tujuan tersebut makan langkah-lang yang dilakukan meliputi pertama menentuan populasi dan sample responden dalam hal ini adalah toko-toko konvensional yang berjualan produk kosmetik, berada di Kecamatan Singosari-Malang-Jawa Timur-Indonesia sejumlah 300 toko, kedua membuat kuesioner selanjutnya disebarkan kepada responden sesuai jumlah sample yang telah dihitung dalam hal ini menggunakan rumus Bernoulli, ketiga membuat kuesioner untuk mendapatkan data penilaian berpasangan antar kriteria dengan skala 1-9, selanjunya data diolah dengan menggunakan metoda Analytical Hierarchy Process (AHP). Hasil dari penelitian ini diperoleh 5 jenis kriteria yaitu kriteria 1: Biaya Promosi diToko online-shop terjangkau, kriteria 2: Sikap Admin online-shop dalam menjalin relationship dengan para penjual, kriteria 3: Tampilan Web jelas dan dapat dimengerti, krioteria 4: Banyak subsidi Ongkos Kirim, Kriteria 5: banyak menyediakan Voucher Discount, dengan besarnya bobot kriteria masing-masing kriteria 1: 0,291, kriteria 2: 0,205, kriteria 3:0,256, kriteria 4: 0,125 dan kriteria 5: 0,122. Kesimpulan bobot kriteria yang paling diperlukan dan paling menjadi perhatian adalah kriteria Biaya Promosi di Toko online-shop terjangkau.
\end{abstract}

Kata Kunci: Analytical Hierarchy Process (AHP), Kriteria, online-shop

\section{Pendahuluan}

Perkembangan Online-Shop melalui media internet telah tumbuh pesat di Indonesia, bahkan sudah sangat dikenal baik oleh masyarakat, berbagai daya tarik telah ditawarkan dalam berbelanja dari berbagai jenis produk dan jasa diantaranya adalah diskon harga dan bebas ongkos kirim. Berbagai strategi dalam menawarkan produk dan jasa menjadi daya tarik tersendiri bagi konsumen yang akan berbelanja dalam menjatuhkan pilihan pada online-shop yang akan menjadi pilihan. Konsep berbelanja melalui online-shop, menyediakan banyak kelebihan dan kemudahan jika dibandingkan dengan konsep belanja pada toko konvensional, Selain proses transaksi dapat menjadi lebih cepat, pada online shop dapat memangkas banyak biaya operasional, biaya tenaga kerja, biaya kurir, sewa lahan toko dan sebagainya [1-2]. Dengan demikian, perusahaan online-shop berlomba-lomba untuk mendapatkan pangsa pasar yang potensial untuk memenangkan persaingan tersebut. 
Tabel 1. Top Rank 3 online shop yang ada di Indonesia

\begin{tabular}{|c|c|c|c|c|c|}
\hline \multicolumn{2}{|c|}{ Quartal 1 - 2019} & \multicolumn{2}{|c|}{ Quartal 2 - 2019} & \multicolumn{2}{|c|}{ Quartal 3 - 2019} \\
\hline Online-shop & $\begin{array}{c}\text { Pengunjung } \\
\text { web / per- } \\
\text { bulan }\end{array}$ & $\begin{array}{l}\text { Marketplace } \\
\text { Onlineshop }\end{array}$ & $\begin{array}{l}\text { Pengunjung } \\
\text { web / per- } \\
\text { bulan }\end{array}$ & $\begin{array}{c}\text { Marketplace } \\
\text { Onlineshop }\end{array}$ & $\begin{array}{l}\text { Pengunjung } \\
\text { web / per- } \\
\text { bulan }\end{array}$ \\
\hline $\begin{array}{l}\text { Tokopedia } \\
\text { tog }\end{array}$ & $137,200,900$ & $\begin{array}{l}\text { Tokopedia } \\
\text { कo } \\
\text { tokopedia }\end{array}$ & $140,414,500$ & Tokopedia & $65,953,400$ \\
\hline $\begin{array}{l}\text { Bukalapak } \\
\text { BL } \\
\text { Bukalapak }\end{array}$ & $115,256,600$ & $\begin{array}{l}\text { Shopee } \\
\text { S } \\
\text { Shopee }\end{array}$ & $90,705,300$ & $\begin{array}{l}\text { Shopee } \\
\text { S } \\
\text { Shopee }\end{array}$ & $55,964,700$ \\
\hline $\begin{array}{l}\text { Shopee } \\
\text { S } \\
\text { Shopee }\end{array}$ & $74,995,300$ & $\begin{array}{l}\text { Bukalapak } \\
\text { BL } \\
\text { Bukalapak }\end{array}$ & $89,765,800$ & $\begin{array}{l}\text { Bukalapak } \\
\text { BL } \\
\text { Bukalapak }\end{array}$ & $42,874,100$ \\
\hline
\end{tabular}

Sumber: https://iprice.co.id/insight.co

Dari tabel diatas menggambarkan 3 online-shop meliputi Tokopedia, Bukalapak dan Shopee terlihat bahwa pada Quartal 1,2,3 tahun 2019 jumlah pengunjung terbanyak adalah pada Tokopedia sebesar 137.200.900 pengunjung (Quartal 1), 140.414.500 pengunjung (Quartal 2), dan 65.953.400 pengunjung (Quartal 3), hal ini menggambarkan bahwa Tokopedia merupakan online-shop yang paling diminati masyarakat. Hal ini menggambarkan Tokopedia memiliki keunggulan dibandingkan dengan Bukalapak dan Shopee dalam memberikan pelayanan kepada konsumen dan konsumen meminati apa saja yang menjadi daya tarik untuk mengunjungi Tokopedia. Hal ini juga berlaku bagi pedagang atau produsen yang memiliki suatu produk ingin memasarkan produknya melalui onlineshop, pertanyaannya adalah online-shop mana sebagai pasar yang paling cocok untuk suatu produk akan dipasarkan. Pemilihan online-shop terbaik sangat ditentukan oleh kriteria yang dibangkitkan, kriteria apa saja yang akan menjadi ukuran penilaian konsumen?.kriteria menjadi hal penting dalam pembuatan keputusan disamping itu terkait dengan keputusan yang kompleks mempertimbangkan qualitative dan quantitative multi-criteria, dalam penelitian pemilihan supplyer yang terbaik, keputusan pemilihan didasarkan pada 4 kriteria meliputi price, quality, logistic, dan service [3-4].

Berkaitan dengan hal tersebut maka pada penelitian ini akan difokuskan pada pembangktan kriteria dan melakukan penilaian kriteria dengan cara pemberian bobot kriteria online-shop untuk produk-produk kosmetik.

\section{Metode}

Material yang digunakan dalam penelitian ini adalah kuesioner ada 3 (tiga) jenis kuesioner, pertama adalah kuesioner 1 untuk menentukan ktriteria penilaian online-shop, dan kedua kuesioner 2 untuk penilaian berpasangan dari masing-masing kriteria, ketiga kuesioner 3 untuk penilaian berpasangan dari masing-masing alternatif untuk setiap kriteria.

Langkah awal dari penelitian ini adalah menentukan alternatif online-shop dalam hal ini nama online-shop adalah online-shop A, online-shop B dan online-shop $\mathrm{C}$, kemudian menentukan populasi dan sampel menggunakan rumus Bernoulli, setelah itu menyebarkan kuesioner 1 untuk mendapatkan kriteria yang diperlukan dalam penilaian online-shop, bahwa penentukan kriteria dapat diurai lagi menjadi sub-sub kriteria, selanjutnya menyebarkan kuesioner 2 untuk mendapatkan nilai kriteria dengan menggunajan skala 1-9 [5], berikutnya mengolah data perbandingan berpasangan mengguanakan Metoda Analytical Hierarchy Process (AHP ) [6-8]. 
Adapun objek yang digunakan dalam pengambilan sampling pada peneltian ini adalah di toko-toko yang berlokasi di sekitar Kecamatan Singosari, Malang, sedangkan pengambilan data sampling sendiri dilakukan pada awal bulan Oktober tahun 2019 sampai bulan Januari tahun 2020.

\section{Hasil dan Pembahasan}

Dari 300 kuesioner yang disebarkan, 14 kuesioner yang tidak kembali, 4 kuesioner dianggap salah karena jawabannya tidak lengkap, dan 11 kuesioner dianggap error karena toko yang mendapat kuesioner diketahui ternyata tidak menjual produk kosmetik.

Berdasarkan rumus Bernoulli, maka jumlah minimum sampel yang diperlukan dimana :

$\mathrm{n}=\frac{\left(Z_{a} / 2\right)^{2} p \cdot q}{e^{2}}$

Dimana:

$\mathrm{n}=$ jumlah sampel

$\left(Z_{a} / 2\right)=$ nilai distribusi normal dengan tingkat kepercayaan $95 \%$

$\mathrm{e}=$ Tingkat kesalahan yang telah ditentukan, yaitu sebesar $10 \%$ atau 0,1

$\mathrm{p}=$ Proporsi jumlah kuesioner yang dianggap benar.

$\mathrm{q}=$ Proporsi jumlah kuesioner yang dianggap salah.

Sehingga :

$\mathrm{n}=\frac{\left(Z_{a} / 2\right)^{2} p \cdot q}{e^{2}}$

$\mathrm{n}=\frac{1,96^{2}(282 / 300)(11 / 300)}{0,1^{2}}$

$\mathrm{n}=13,54$ atau sama dengan 14

Maka diperoleh jumlah sampel minimum sebesar 14 responden.

Tabel 3. Kriteria Penilaian online-shop hasil dari Kuesioner

\begin{tabular}{|c|l|}
\hline No. & \multicolumn{1}{|c|}{ Kriteria } \\
\hline 1. & Biaya Promosi di Toko online-shop \\
\hline 2. & Sikap Admin online-shop dalam menjalin relationship \\
\hline 3. & Tampilan Web jelas dan dapat dimengerti \\
\hline 4. & Banyak Subsidi Ongkir \\
\hline 5. & Sering menyediakan Voucher Diskon \\
\hline
\end{tabular}

Tabel 4. Pairwise Comparison Antar Kriteria Hasil dari Aplikasi Expert Choice (Responden 1)

\begin{tabular}{|c|c|c|c|c|c|}
\hline Kriteria & 1 & 2 & 3 & 4 & 5 \\
\hline 1 & & 5,000 & 3,000 & 5,000 & 1,000 \\
\hline 2 & & & 4,000 & 6,000 & 9,000 \\
\hline 3 & & & & 5,000 & 3,000 \\
\hline 4 & & & & & 2,000 \\
\hline 5 & Incon:0,06 & & & & \\
\hline
\end{tabular}


Jurnal Teknologi dan Manajemen Industri, Vol. 6 No. 2 , Agustus 2020

Pascasarjana Institut Teknologi Nasional Malang

$$
\mathrm{CR}=0,06<0,1 \text { (konsisten) }
$$

Pada Tabel 4. Hasil penilaian berpasangan untuk responden 1, diperoleh nilai Consistensi Ratio (CR) $=0,06$, karena kurang dari 0,1 maka hasil tersebut konsisten dan dapat digunakan pada langkah berikutnya.

Tabel 5. Pairwise Comparison Antar Kriteria dari Aplikasi Expert Choice

\begin{tabular}{|c|c|c|c|c|}
\hline \multirow[b]{2}{*}{ Biaya promosi di toko online } & \multicolumn{4}{|c|}{ Biaya pron Tampilan w Sikap admi Banyak subs Sering menyet } \\
\hline & 2.104 & 1.239 & 3.28 & 2.11 \\
\hline Tampilan web jelas dan dapat dimengerti & & 1.787 & 1.16 & 1.098 \\
\hline Sikap admin toko online dalam menjalin relationship & & & 2.288 & 1.648 \\
\hline Banyak subsidi ongkir & & & & 1.003 \\
\hline Sering menyediakan voucher diskon & Incon: 0.08 & & & \\
\hline
\end{tabular}

Tabel 6. Pairwise Comparison Antar Kriteria Hasil dari Aplikasi Expert Choice (Gabungan Responden 1 sampai dengan 14 menggunakan rata-rata geometrik)

\begin{tabular}{|c|c|c|c|c|c|}
\hline Kriteria & 1 & 2 & 3 & 4 & 5 \\
\hline 1 & & 2,104 & 1,239 & 3,280 & 2,110 \\
\hline 2 & & & 1,787 & 1,160 & 1,098 \\
\hline 3 & & & & 2,288 & 1,648 \\
\hline $\mathrm{s} 4$ & & & & & 1,003 \\
\hline 5 & Incon:0,08 & & & & \\
\hline
\end{tabular}

Pada Tabel 6. Merupakan hasil penilaian berpasangan gabungan dari 14 responden dimana nilai tersebut diperoleh dari hasil perhitungan rata-rat geometrik, dan nilai CR nya $=0,08$ lebih kecil dari 0,1 maka data konsisten dan dapat digunakan untuk proses selanjunya.

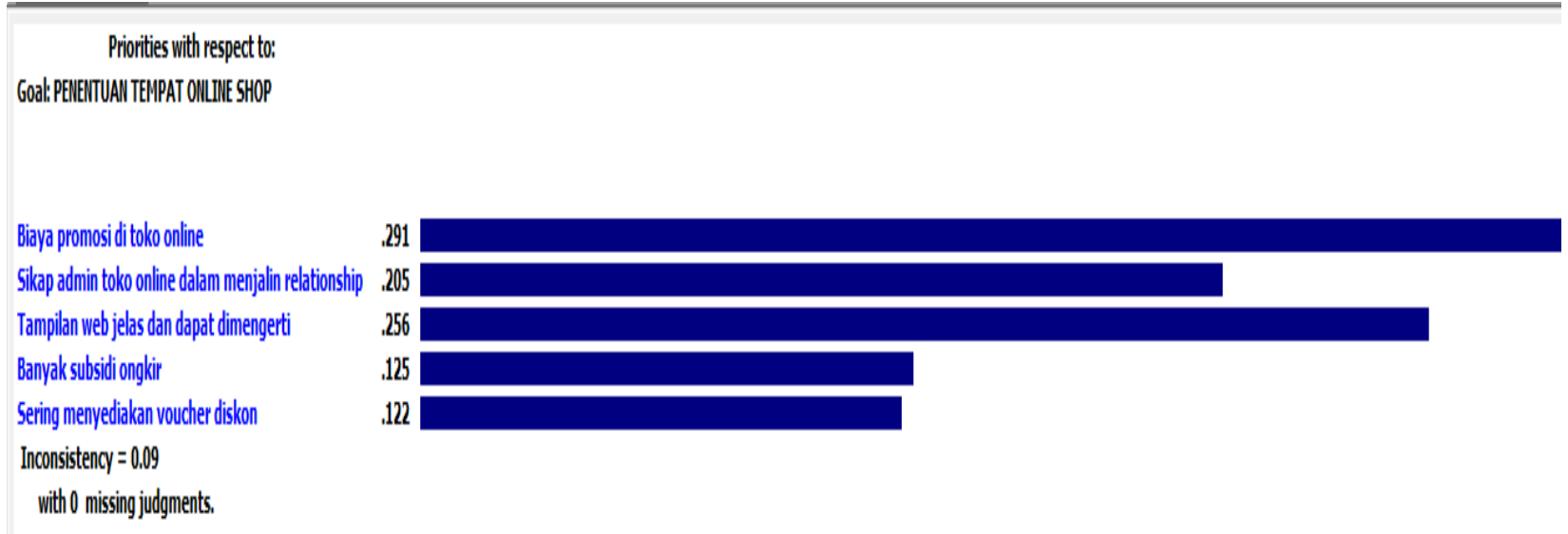

Gambar 1. Bobot Kriteria Hasil dari Aplikasi Expert Choice 
Tabel 7. Bobot Kriteria Hasil dari Aplikasi Expert Choice

\begin{tabular}{|c|l|c|}
\hline No. & \multicolumn{1}{|c|}{ Kriteria } & Bobot \\
\hline 1. & Biaya Promosi di Toko online-shop & 0,291 \\
\hline 2. & Sikap Admin online-shop dalam menjalin relationship & 0,205 \\
\hline 3. & Tampilan Web jelas dan dapat dimengerti & 0,256 \\
\hline 4. & Banyak Subsidi Ongkir & 0,125 \\
\hline 5. & Sering menyediakan Voucher Diskon & 0,122 \\
\hline
\end{tabular}

Pada Tabel 7. Jika kita ambil tiga rangking tertinggi maka Kriteria 1 mendapatkan bobot tertinggi yaitu kriteria Biaya Promosi di Toko online-shop, sedangkan rangking kedua adalah kriteria Tampilan Web jelas dan dapat dimengerti selanjutnya rangking ketiga adalah kriteria sikap admin online-shop dalam menjalin relationship terhadap konsumen, kriteria dengan bobot tertingi sebagai dasar penentuan pembuatan keputusan [9]. temuan penting dalam rangking prioritas yang diperoleh dari $A H P$ merupakan gambaran preferensi pembuatan keputusan [10].

\section{Kesimpulan}

Bobot kriteria yang paling diperlukan dan paling menjadi perhatian adalah kriterial Biaya Promosi di Toko online-shop terjangkau. Kriteria dengan prioritas tertinggi menggambarkan preferensi konsumen dalam memberian penilaian.

Hasil penghitungan aggregate/prty (priority) dapat dilihat bahwa setiap alternatif unggul dalam masing-masing kriteria

Pada pengolahan data menggunakan Expert Choice diperoleh derajat inkonsistensi keseluruhan sebesar 0,05 yang berarti tingkat kesalahan dalam pengambilan keputusan pemilihan online shop tergolong rendah yaitu $\mathrm{CR}<0,1$.

\section{Daftar Pustaka}

[1] Amir, Rizal, K dan Christian, A. 2016. Pemilihan Penyedia Onlineshop Prioritas Dengan Metode Analytical Hierarchy Process (AHP).

[2] S. Harianto and E. Nursanti, "Green Quality Improvement Using Six Sigma Method," Int. J. Innov. Sci. Res. Technol., vol. 5, no. 8, pp. 583-588, 2020, doi: 10.38124/ijisrt20aug266.

[3] Ramlan R. and Qiang L. W., 2014. An Analytic Hierarchy Process Approach For Supplier Selection: A Case Study. 3rd International Conference on Global Optimization and Its Application (ICoGOIA ).

[4] Nismah Panjaitan and Bayu Suwandira, "Sistem Pendukung Keputusan Pemilihan Jasa Online Shop dengan Menggunakan Metode AHP (Analytic Hierarchy Process)," Talent. Conf. Ser. Energy Eng., vol. 2, no. 3, pp. 616-623, 2019, doi: 10.32734/ee.v2i3.787.

[5] Waris M., Panigrahi S., Mengal A., Iqbal M. Soomro, Mirjat N. H., Ullah M., Azlan S. Z., Khan A. 2019. An Application of Analytic Hierarchy Process (AHP) for Sustainable Procurement of Construction Equipment: Multicriteria-Based Decision Framework for Malaysia. Mathematical Problems in Engineering, Vol. 2019.

[6] Saaty, T. L., 1980. The Analytic Hierarchy Process: Planning, Priority Setting, Resources Allocation. London: McGraw-Hill.

[7] A. Syamsudin, E. Nursanti, and E. Adriantantri, "Analisis Pemilihan Supplier Yang Tepat Untuk Produk Gigi Palsu (Studi Kasus Di CV. Brother Dent),” J. Teknol. Dan Manaj. Ind., vol. 3, no. 2, pp. 1-7, 2017, doi: 10.36040/jtmi.v3i2.176. 
Jurnal Teknologi dan Manajemen Industri, Vol. 6 No. 2 , Agustus 2020

Pascasarjana Institut Teknologi Nasional Malang

[8] Y. A. Prayoga, E. Nursanti, and T. Priyasmanu, "Sistem Pendukung Keputusan Pemilihan Supplier Botol Galon Menggunakan Metode Analytical Hierarchy Process (AHP)," J. Teknol. Dan Manaj. Ind., vol. 2, no. 2, pp. 29-35, 2016, doi: 10.35457/antivirus.v10i2.163.

[9] Balubaid, M. and Alamoudi, R. 2015. Application of the Analytical Hierarchy Process (AHP) to Multi-Criteria Analysis for Contractor Selection. American Journal of Industrial and Business Management, 5, 581-589.

[10] Haw H. F., Rashid S. H. A., and Raja Ariffin Raja Ghazilla R. A. R., 2016. Analytic Hierarchy Process-Based Analysis to Determine the Barriers to Implementing a Material Efficiency Strategy: Electrical and Electronics' Companies in the Malaysian Context. Sustainability, 8 